\title{
Increasing Prospects for Nanofibers and Nanofiltration
}

\section{Samuel C Ugbolue*}

Department of Materials and Textiles, University of Massachusetts, USA

Nanofiltration remains a veritable platform to address the problem of developing functional membranes that can simultaneously remove various organic and metal pollutants from waste water. Nanofiltration (NF) is a cross-flow filtration technology which ranges somewhere between Ultrafiltration (UF) and Reverse Osmosis (RO). Industrial applications of nanofiltration are quite common in the food and dairy sector, in chemical processing, in the pulp and paper industry, and in textiles, although the chief application continues to be in the treatment of fresh, process and waste waters. Indeed, advances in nanofiltration can accelerate the realization of the goal to provide affordable clean water for the developing countries. Increasingly, greater research efforts are being directed towards the production of nanofibers and nanocomposite fabrication. Tremendous research activities have continued to exploit electrospinnng [1-4] as the most notable technology available today that has been conveniently deployed for nanofiber production, although there is need for the full commercialization of the process. It is recognized that when nanofibers with high surface areas are functionalized by incorporation of photocatalytic catalysts and/ or surface modification, such nanofibers can be applied to membrane filters to capture various organic and metal pollutants in wastewater treatment.

The BCC Research LLC in their Market Research Report showed that the global market for nanofiltration membranes increased from $\$ 89.1$ million in 2006 to an estimated $\$ 310.5$ million by 2012 , a Compound Annual Growth Rate (CAGR) of $26.1 \%$. The water treatment sector projected to account for $72.7 \%$ of total revenues in 2007, worth an estimated $\$ 70.9$ million in 2007 is expected to reach $\$ 238.2$ million by 2012, a CAGR of $27.4 \%$. However, Frost and Sullivan in their US Membrane Separation Systems Market (2006) forecast the market to grow at a Compound Annual Growth Rate (CAGR) of 34.3\% through 2015, and at a 37.2\% CAGR from 2015 through 2020, reaching nearly $\$ 2.2$ billion in total revenues by 2020 . Thus, this editorial highlights some of the developments and advances in nanofiltration and expanding areas of application.

The large diversity of membrane separation processes results in a different optimization of membrane materials and structures for each process. Van der Bruggen et al. [5], have shown the extent to which a single membrane type can be used in gas separation, pervaporation, and nanofiltration. Interpretation of transport and separation properties has led to the conclusion that the membrane SolSep 3360 is a multifunctional membrane fulfilling all requirements for the three separation processes. This can be achieved by keeping a good balance between the thickness of the top layer, steric hindrance during transport, and the effect of hydrophobicity/hydrophilicity.

Colloidal fouling is still one of the major impediments for the implementation of membrane processes, e.g. in the purification of surface water. Effects of fouling for several representative nanofiltration membranes during filtration of several types of colloids in different circumstances ( $\mathrm{pH}$, ionic strength) have been studied by Boussu et al. [6]. It was shown that not only the membrane, but also the colloid characteristics are crucial to control membrane fouling. Also, large colloids with a negative surface charge seem to be the most beneficial for a nanofiltration process at neutral $\mathrm{pH}$. Changing the $\mathrm{pH}$ changes the interaction forces between membranes and colloids and also between the colloids themselves. Thus a higher ionic strength leads to more membrane fouling in case of membranes with small pore sizes.

In another study Lovell et al. [7] showed that present technological composite polymer membranes for water purification are limited in application and practical life by their susceptibility to foul with concurrent reduction in membrane permeability. Recent developments in graft copolymers have produced fouling resistant nanofiltration membranes. Specifically, polyacrylonitrile-graft-poly (ethylene glycol) (PAN-g-PEG) coated membranes with size selectivity have been reported. Also Lovell et al. [7] reported on similar membranes with the addition of grafted, charged groups to impart charge selectivity to the filtration properties of the membrane and permit the exclusion of salts. A membrane coated with a negative-charged, sulfopropyl-modified variant of the copolymer retains much of the fouling resistance while retaining simple salts. The specificity of the coated membrane and the effect of environment on its properties were reported. Pesticides and hardness can be removed in one step [8]. The experimental retentions indicate that NF-70 is a suitable membrane for removal of pesticides. The matrix of the ground waters caused an increase of the pesticide retention, together with a decrease of the water flux through the membrane. Nanofiltration membranes (NF) are used in pretreatment unit operations in both thermal and membrane seawater desalination processes and as partial demineralization to seawater. In order to predict NF membrane performance, a systematic study on the filtration performance of selected commercial NF membranes against seawater is presented [9]. The NF90 membrane was able to reject both monovalent and divalent of all studied mixtures and seawater with very reasonable values but at a relatively low flux. It reduced the salinity from 38 to $25.5 \mathrm{~g} / \mathrm{L}$ using a single-stage NF membrane at 9 bars. This makes NF90 more suitable for the pretreatment in desalination processes. NF270 can reject monovalent ions at relatively low values and divalent ions at reasonable value.

French research [10] has led to development of a selective nanofiltration membrane, now being used to convert river water into potable water. The Filmtec NF200 nanofiltration membrane can remove harmful pollutants (herbicides and pesticides) from river water while leaving beneficial dissolved minerals such as $\mathrm{Ca}^{2+}$ and $\mathrm{Mg}^{+}$. The Dow Filmtec membranes are based on proven, spiral-wound, thin-film composite polyamide membranes and consist of 3 layers, an ultra-thin polyamide barrier layer, a micro-porous polysulfone interlayer, and

*Corresponding author: Samuel C Ugbolue, Department of Materials and Textiles, University of Massachusetts, USA, E-mail: sugbolue@gmail.com

Received November 05, 2012; Accepted November 06, 2012; Published November 13, 2012

Citation: Ugbolue SC (2012) Increasing Prospects for Nanofibers and Nanofiltration. J Textile Sci Eng 2: e112. doi:10.4172/2165-8064.1000e112

Copyright: (c) 2012 Ugbolue SC. This is an open-access article distributed under the terms of the Creative Commons Attribution License, which permits unrestricted use, distribution, and reproduction in any medium, provided the original author and source are credited. 
a high strength polyester support web. The polyamide barrier layer provides high water flux, superior salt and $\mathrm{SiO}_{2}$ rejection, and excellent chemical resistance. The thick, microporous polysulfone support layer provides the necessary porosity and strength characteristics and restricts compaction under the pressure of reverse osmosis operation. Filmtec membrane performance in nanofiltration and reverse osmosis applications has been well documented; they have high dissolved solids and organic rejection, low pressure operation, high $\mathrm{pH}$ stability, and are structurally very strong.

In spite of the progress so far achieved, there is concerted effort to search for a standard method for the characterization of organic solvent nanofiltration. Toh et al. [11], described a method for the determination of the relationship between solute molecular weight and rejection, often referred to as the Molecular Weight Cut Off (MWCO) of the Organic Solvent Nanofiltration (OSN) membranes. This method utilizes a homologous series of styrene oligomers spanning the nanofiltration range (200-1000 g mol-1). Good separation of the individual oligomers was achieved using liquid chromatography with a reverse phase $\mathrm{C} 18$ column. The good solubility of the styrene oligomers in many organic solvents makes cross comparison of membrane performance across these solvents possible. This method also allows the determination of the molecular weight at which a rejection of $>99.9 \%$ occurs in different solvents, making it a useful tool to test membrane and equipment integrity.

The work by Ksontini et al. [12] dealt with the preparation and the characterization of cellulose acetate membranes for the textile water treatment by Ultrafiltration (UF) and Nanofiltration (NF). The evolution of flow was analyzed and treated by a comparative study of the $\mathrm{pH}$ and time effects on the performances regeneration of prepared membranes. Also, the hybrid technology of flocculant sedimentationtubular UF-NF-NF was applied to treat city landfill leachate [13]. The influence of different operating conditions, such as pretreatment method, membrane modules and operating pressure, on landfill leachate treatment was investigated. Only around $10 \%-15 \%$ of the permeate solution remained as the concentrated leachate, which may return to landfill pond or be incinerated after dehydration.

Lin et al. [14] have proposed a continuous process for solvent exchange, a key unit operation for organic synthesis in pharmaceutical manufacturing. This process comprises a counter-current membrane cascade using Organic Solvent Nanofiltration (OSN) membranes. The effect of process parameters, such as number of stages and flow rate ratio of replacing solvent to initial solvent, on solvent exchange performance are tested through simulations and experiments. Experimental results showed $47.8 \%, 59.2 \%$, and $75.3 \%$ solvent exchange for single-stage, two-stage and three-stage cascades, values which are close to the $50.0 \%, 66.6 \%$, and $75.0 \%$ respectively predicted by simulations. In general, the feasibility of OSN membrane cascades for continuous solvent exchange is demonstrated in this work. Thus, it is evident that providing nanofiltration methods to developing countries, to increase their supply of clean water, have become a very inexpensive method compared to conventional treatment systems.

\section{References}

1. Buer A, Ugbolue SC, Warner SB (2001) Electrospinning and Properties of Some Nanofibers. Text Res J 71: 323-328.

2. Kalayci VE, Patra PK, Buer A, Ugbolue SC, Kim YK, et al. (2004) Fundamental investigations on electrospun fibers. J Adv Mater 36: 43-45.

3. Kalayci VE, Patra PK, Kim YK, Ugbolue SC, Warner SB (2005) Charge consequences in electrospun polyacrylonitrile (PAN) nanofibers. Polymer 46: 7191-7200.

4. http://www.donaldson.com/en/filtermedia/nanofibers/index.html

5. Van der Bruggen B, Jansen JC, Figoli A, Geens J, Boussu K, et al. (2006) Characteristics and performance of a "universal" membrane suitable for gas separation, pervaporation, and nanofiltration applications. J Phys Chem B 110: 13799-13803.

6. Boussu K, Belpaire A, Volodin A, Haesendonck CV, Van der Meeren P, et al. (2007) Influence of membrane and colloidcharacteristics on fouling of nanofiltration membranes. J Membrane Sci 289: 220-230.

7. Lovell NG, Mayes AM, Taniguchi I, Asatekin A (2007) Charged polymer nanofiltration membranes for selective retention. The 233rd ACS National Meeting, Chicago, USA.

8. Van der Bruggen B, Schaep J, Maes W, Wilms D, Vandecasteele C (1998) Nanofiltration as a treatment method for the removal of pesticides from groundwaters. Desalination 117: 139-147.

9. Hilal N, Al Zoubi H, Darwish NA, Mohammad AW (2006) Performance of Nanofiltration Membranes in the Treatment of Synthetic and Real Seawater. Separ Sci Technol 42: 493-515.

10. Nicoll H (2001) Nanofiltration makes surface water drinkable. Filtr Separat 38 : 22-23.

11. Toh YHS, Loh XX, Li K, Bismarck A, Livingston AG (2007) In search of a standard method for the characterisation of organic solvent nanofiltration membranes. J Membrane Sci 291: 120-125

12. Ksontini K, Ferjani E, Roudesli MS (2006) Improvement of textile waste water treatment by combination of ultrafiltration and nanofiltration membrane processes. Journal de la Societe Chimique de Tunisie 8: 77-88.

13. Xu-Min H, Shao-Hong C, Guo-Mei H, Bi-Rong Z, Ma-Tai D, et al. (2006) Landfil leachate treatment by nanofiltration process. Huaxue Gongcheng 34: 48-51.

14. Lin JCT, Livingston AG (2007) Nanofiltration membrane cascade for continuous solvent exchange. Chem Eng Sci 62: 2728-2736. 